\title{
Opacity is a Matter of Representation: Shimakonde Vowel Harmony and Vowel Reduction
}

\author{
Laura J. Downing \\ Zentrum für Allgemeine Sprachwissenschaft, Berlin
}

\begin{abstract}
As work like McCarthy (2002: 128) notes, pre-Optimality Theory (OT) phonology was primarily concerned with representations and theories of subsegmental structure. In contrast, the role of representations and choice of structural models has received little attention in OT. Some central representational issues of the pre-OT era have, in fact, become moot in OT (McCarthy 2002: 128). Further, as work like Baković (2007) notes, even for assimilatory processes where representation played a central role in the pre-OT era, constraint interaction now carries the main explanatory burden. Indeed, relatively few studies in OT (e.g., Rose 2000; Hargus \& Beavert 2006; Huffmann 2005, 2007; Morén 2006) have argued for the importance of phonological representations. This paper intends to contribute to this work by reanalyzing a set of processes related to vowel harmony in Shimakonde, a Bantu language spoken in Mozambique and Tanzania. These processes are of particular interest, as Liphola's (2001) study argues that they are derivationally opaque and so not amenable to an OT analysis. I show that the opacity disappears given the proper choice of representations for vowel features and a metrical harmony domain.
\end{abstract}

\section{Introduction}

Phonological generalizations lead to derivational opacity, as defined by McCarthy (1999), when they are either not surface true or not surface apparent. A process is not surface-true when it underapplies: its context is met, yet the process fails to apply. A process is not surface-apparent when it overapplies: its context is not met, yet the process applies. (See Baković 2007a for a recent survey of opacity types.) Constraint ranking and interaction account for many cases of opacity which fit this definition. However, there are also problematic cases which seem to require reference to an intermediate level of representation besides the input and output representations allowed in standard Optimality Theory (OT). In the OT literature, one typical response to these cases of opacity 
is to admit limited serialism into OT, allowing for a constrained set of intermediate representations (see, e.g., Ettlinger 2008; Kiparsky 2000; Rubach 2003; Bermudez-Otero, forthcoming; and papers in Vaux \& Nevins (2008) for detailed recent discussion of arguments in favor of serialism in phonology). Another is to propose new types of Correspondence which formalize intermediate representations in a way said to be compatible with nonderivational OT: e.g., sympathy theory, comparative markedness or turbid constraints (McCarthy 1999, 2003; Ito \& Mester 1997, 2003a; Goldrick 2000).

Another response is to show that opacity is a feature of a particular analysis of a particular problem; it is not inherent to a data set. Adopting a different, equally well-motivated set of generalizations or representations can 'clarify' processes characterized as opaque by other OT practitioners. Examples of this approach include Harris's (1997) and Downing's (2006) reanalyses of German "Spitznamen" (opaque in Ito \& Mester 1997), Downing's (2005) reanalysis of pre-NC compensatory lengthening in Bantu languages (opaque in Goldrick 2000), Green's (2007) reanalysis of Tiberian Hebrew epenthesis (opaque in McCarthy 1999), Krämer's (2008) reanalysis of English $r$-loss or intrusion (opaque in McCarthy 1993 and Orgun 2001), Mielke et al.'s (2003) reanalysis of Sea Dayak (opaque in McCarthy 2003). (See van der Hulst \& Ritter (1999b) for other examples.)

In this paper, I adopt the second approach to reanalyze a set of processes related to vowel harmony in Shimakonde that have been argued to be opaque by Goldrick (2000), Ettlinger (2008) and Liphola (2001). I show that opacity vanishes under an alternative theory of representation. The goal of the paper is to show, echoing Uffmann (2007), that the choice of representations is as crucial to an OT analysis as the choice of constraints and constraint interactions.

The paper is organized as follows. In section 2, I present the data to be analyzed, namely, Shimakonde vowel height harmony ( $\mathrm{VHH}$ ) and the processes of vowel coalescence and vowel reduction that can make the output of harmony opaque. In section 3, I develop an analysis of $\mathrm{VHH}$, crucially adopting the element theory of vowel representations, and a markedness licensing approach to harmony. In section 4, I extend this analysis to account for vowel reduction and coalescence, and show that it eliminates the apparent opacity in the interaction of these processes with $\mathrm{VHH}$.

\section{Vowel height harmony (VHH), vowel reduction and coalescence}

Shimakonde is a Bantu language (P20) spoken in Mozambique and Tanzania. The source of the data and generalizations discussed is Liphola's (2001) study of the Mozambican dialect, his native language. (Kraal (2005) discusses similar patterns from a Tanzanian dialect.) Shimakonde has what Hyman (1999: 238) 
calls 'canonical Bantu Vowel Height Harmony' (VHH), with the following characteristic properties. First, it is subject to morphological conditioning. It is Root-controlled and motivates alternations in suffixes following the verb root, except that it does not apply to the final vowel morpheme (FV). It also does not apply to prefixes. The bolded domain in (1) summarizes these generalizations: ${ }^{1}$

\section{(1) $[[$ Prefixes $][[\underline{\text { Root }}+$ Derivational Suffixes $]$ FV $]$}

Canonical VHH is also subject to phonological conditioning. As shown in (2c, d), below, only mid Root vowels [e, o] trigger harmony and are the output of harmony. Peripheral vowels $-[\mathrm{i}, \mathrm{u}, \mathrm{a}]-$ do not trigger harmony. As shown in $(2 \mathrm{a}, \mathrm{b}, \mathrm{e})$, they are all followed by high vowels. The low vowel [a] is also opaque. It does not undergo harmony and blocks the spread of harmony. Finally, non-initial back vowels often harmonize only to the back mid vowel, [o], as shown in (2f) vs $(2 \mathrm{~g})$. Note in (2), that the Shimakonde VHH patterns are essentially identical to those discussed in Beckman's (1997) OT analysis of Shona VHH:

(2) Shona (Beckman 1997: 1)

(a) -bvis-a 'remove' -bvis-ik-a

(b) -bvum-a 'agree' -bvum-is-a

(c) -tond-a 'face' -tond-es-a

(d) -per-a 'end'

(e) -shamb-a 'wash'

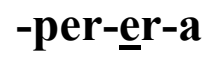

-shamb-is-a

-svetukk-a 'uproot'

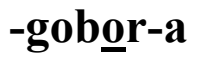

Shimakonde (Liphola 2001: 147)

-pínd-a 'bend' -pind-íik-a

-púút-a 'wash' -put-ííl-a

-tóót-a 'sew' -tot-éék-a

-péét-a 'sift' -pet-éél-a

-páát-a 'get' -pat-ííl-a

-tééng-a 'set a -téng-úúl-a

fire'

‘cough' -kólómóól-a

As Liphola (2001) shows, derivational opacity arises when vowel coalescence and vowel reduction interact with VHH. In Shimakonde, as in many Bantu languages (see e.g. Casali 1998; Downing 1995), vowel hiatus across the prefix $+[$ Root boundary is resolved by coalescence, accompanied by lengthening: $\mathrm{a}+[\mathrm{i}, \mathrm{e}>\mathrm{ee} ; \mathrm{a}+[\mathrm{u}, \mathrm{o}>$ oo. Since the output of coalescence in this context is a Root-initial mid vowel, we would expect vowels following it in the domain to harmonize to mid. However, only some coalesced mid vowels $(3 a, b)$ are followed by mid vowels, while others $(3 \mathrm{c}, \mathrm{d})$ are followed by [+high] vowels.

1 The domain of VHH bolded in (1) is variously termed the verbal base (Harris 1987; Harris \& Lindsey 1995), the prosodic trough (Hyman 1998), or the prosodic stem (Downing 1999; Mutaka 1994). It is beyond the scope of this paper to discuss the morphological domain of VHH. See the work cited for further discussion of phonological processes like VHH which motivate the domain. 
(3) Shimakonde vowel coalescence and vowel harmony (Liphola 2001: 101, 178)
(a) $/ \mathrm{a}+[\mathrm{e} / /$ vandá-[ep-íl-a/
(b) $/ \mathrm{a}+[\mathrm{o} / /$ vá-[óloota/
va-ndeépeéla
'they will harvest for'
(c) $\quad / a+[i / /$ vandá-[itík-a/
vóóloota
'when pointing'
(d) $/ \mathrm{a}+[\mathrm{u} / /$ vandá-[ukúl-a/
va-ndeétíka
'they will respond'
va-ndoókuúla
'they will dig'

Coalesced

Gloss

That is, as the result of coalescence VHH is not always surface true. The context for harmony (i.e., a Root-initial mid vowel) occurs in the output of $(3 \mathrm{c}, \mathrm{d})$, yet VHH underapplies in these examples. The input contrast between Root-initial mid vowels and Root-initial high vowels which is lost in the output due to coalescence is indirectly maintained through the underapplication of $\mathrm{VHH}$.

The lengthening accompanying coalescence has also been argued to illustrate opacity, due to what Goldrick (2000) terms overapplication of mora projection. If you assume that vowels are not associated with moras in the input, the long vowel that results from coalescence in (3) is opaque. As only one vocalic root node survives coalescence, there is no motivation in the output for projecting two moras, one for each input vowel:

(4) Opaque compensatory lengthening (Goldrick 2000, fig. (2))

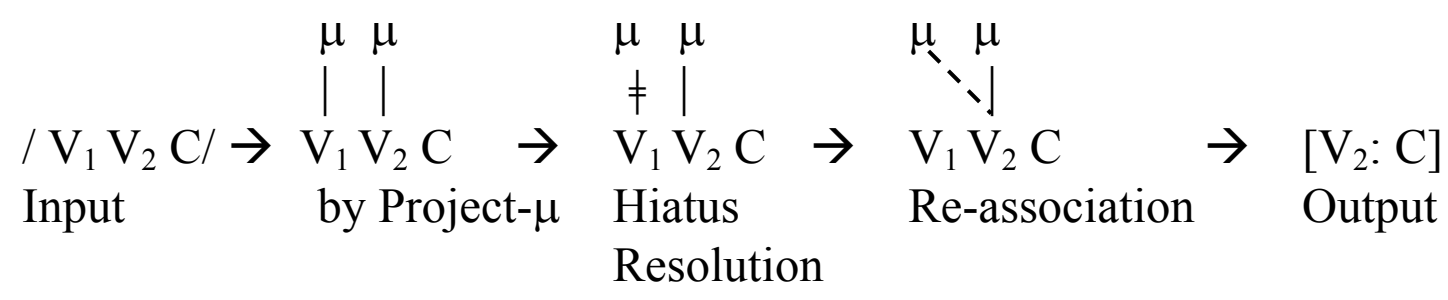

As Liphola (2001) shows, another source of apparent opacity in Shimakonde VHH comes from a process of unstressed vowel reduction. As we see in (5), the penult vowel is systematically stressed (realized as lengthening). Beside the canonical, unreduced VHH pattern, we find a reduced pattern. Pretonic mid vowels optionally neutralize to the low vowel [a]; pretonic peripheral vowels ' $\mathrm{i}$, $\mathrm{u}, \mathrm{a}$ ' do not alternate.

(5) Shimakonde (Liphola 2001: section 5.2)

$\begin{array}{lll}\text { (a) -píind-a 'bend' } & \begin{array}{l}\text { Unreduced } \\ \text {-pind-íík-a }\end{array} & \text { Reduced } \\ & & \end{array}$




$\begin{array}{llllll}\text { (b) -púút-a } & \text { 'wash' } & \text {-put-ííl-a } & & \text { *-pat-íll-a } \\ \text { (c) -tóót-a } & \text { 'sew' } & \text {-tot-éék-a } & \text { OR } & \text {-tat-éék-a } \\ \text { (d) -péét-a } & \text { 'sift' } & \text {-pet-éél-a } & \text { OR } & \text {-pat-éél-a } \\ \text { (e) -páát-a } & \text { 'get' } & \text {-pat-íill-a } & & \end{array}$

Stressed mid vowels retain the input harmonic quality contributed by the Rootinitial syllable, not the [+high] value expected following peripheral [a]. That is, as a result of vowel reduction the context of VHH is not always surface apparent. VHH overapplies in the reduced forms in $(5 \mathrm{c}, \mathrm{d})$ : the context for VHH is not met, yet the process applies to the stressed vowels. (They harmonize with the input mid quality of the Root initial syllable which is lost in the output due to vowel reduction.)

Liphola (2001: 191-194) argues that vowel reduction must be considered a neutralizing process in Shimakonde. As shown in the table in (6), which summarizes a phonetic analysis that Liphola carried out based on his own speech and that of two other native speakers, reduced [a] is not distinct from underlying [a] in either realization or perception. There is no significant difference in the realization of the long [aa]'s, whatever their source and whether they are stressed or unstressed. There is also no significant difference among the short [a]'s, whatever their source:

\begin{tabular}{|c|c|c|}
\hline Type of vowel & Avg F1 & Avg F2 \\
\hline Stressed [aa] & $\mathbf{9 3 1}$ & $\mathbf{1 5 3 0}$ \\
\hline$[\mathrm{aa}]<\mathrm{aa}$ & 926 & 1528 \\
\hline$[\mathrm{aa}]<\mathrm{ee}$ & 916 & 1538 \\
\hline$[\mathrm{aa}]<\mathrm{oo}$ & 911 & 1552 \\
\hline$[\mathrm{a}]<\mathrm{a}$ & 741 & 1558 \\
\hline$[\mathrm{a}]<\mathrm{e}$ & 761 & 1542 \\
\hline$[\mathrm{a}]<\mathrm{o}$ & 814 & 1575 \\
\hline
\end{tabular}

There is, however, a significant difference in the F1 of the long vs. short [a]'s which Liphola (2001) attributes to duration-induced undershoot. Perceptual evidence also shows that reduced [a] neutralizes with phonemic [a]. In a perception experiment of neutralized minimal pairs, Liphola (2001) found that native listeners could only correctly distinguish phonemic and reduced [a]'s $31.86 \%$ of the time, below chance $(=33.3 \%)$. Following Liphola (2001) and 
Crosswhite (2001, 2003), we can conclude, then, that reduction in Makonde involves phonemic neutralization of all non-low vowels to [a] accompanied by duration-induced phonetic undershoot of short [a]. The phonological analysis in section 4, below, accounts only for the phonemic neutralization.

Reduction also interacts with coalescence. Since the output of coalescence is a mid vowel, we would expect all coalesced vowels to undergo pre-tonic mid vowel reduction like other unstressed mid vowels do. However, Liphola (2001) shows that only some coalesced mid vowels $(7 \mathrm{a}, \mathrm{b})$ reduce to $[\mathrm{a}]$, while others do $\operatorname{not}(7 \mathrm{c}, \mathrm{d})$ :

(7) Shimakonde vowel coalescence, harmony and reduction (Liphola 2001: 101, 178)

Input Coalesced Reduced Gloss

(a) /a+[e/ /vandá-[ep-íl-a/ va-ndeépeéla va-ndaápeéla 'they will harvest for'

(b) /a+[o/ /vá-[óloota/ vóóloota vááloota 'when pointing'

(c) /a+[i/ /vandá-[itík-a/ va-ndeétíka *va-ndaátiíka 'they will respond'

(d) /a+[u/ /vandá-[ukúl-a/ va-ndoókuúla *va-ndaákuúla 'they will dig'

Coalescence makes vowel reduction derivationally opaque. The context for reduction (i.e., a pre-tonic mid vowel) is met in the output of $(7 \mathrm{c}, \mathrm{d})$, yet reduction underapplies in examples like these. The output contrast between pretonic mid vowels that do not reduce to [a] $(7 \mathrm{c}, \mathrm{d})$ and pre-tonic mid vowels that do reduce $(7 a, b)$ makes reduction not surface true. ${ }^{2}$

In section 4, I show that if we follow some other previous studies of Bantu VHH, like Goldsmith (1985), Harris (1987), and Steriade (1995), and adopt the element theory of vowel representations, all of these sources of opacity vanish. In the next section, I first motivate element theory by showing how it accounts for the basic VHH patterns illustrated in (2).

2 As Barnes (2006) and Nevins (2007) note, the fact that some non-stressed long mid vowels resulting from coalescence can undergo vowel reduction confirms that reduction is not a purely phonetic process of duration-induced undershoot. Only long stressed vowels resist reduction, showing the process has been phonologized. 


\section{Element theory analysis of VHH in Shimakonde}

In this section, I develop an OT analysis of the central properties of Shimakonde VHH: that it is Root-controlled, involves only mid vowels, and the low vowel is inert and opaque. ${ }^{3}$ As we shall see, these properties fall out from the element theory of representation adopted, and from the related hypothesis that harmony involves positional licensing of markedness asymmetries. To highlight the advantages of the approach adopted here, I begin by presenting an alternative, Beckman's (1997) standard OT analysis of VHH in Shona.

\subsection{Positional faithfulness account of Bantu VHH: Beckman (1997)}

In Beckman's (1997) analysis of VHH in Shona - which basically translates into OT terms underspecified, autosegmental approaches like those reviewed in van der Hulst \& van de Weijer (1995) - the motivation for harmony is gestural uniformity. VHH minimizes the number of different vowel height specifications in the Stem, as some are shared. The direction of harmony falls out from the Root $>>$ Affix asymmetry defined by the ranked POSITIONAL FAITHFULNESS constraints in $(8 \mathrm{a}, \mathrm{b})$. Only mid vowels are involved in VHH because of the HEIGHT MARKEDNESS HIERARCHY in (8c):

(8) Faithfulness constraints defining Root-controlled harmony (Beckman 1997: 14)

(a) IDENT-S1(hi)

A segment in the root-initial syllable in the output and its correspondent in the input must have identical values for the feature [high].

(b) IDENT(hi)

Correspondent segments in the output and input must have identical values for the feature [high].

(c) HeIgHT MARKEDNESS : DOMINANCE HIERARCHY: *MID $>>*$ High, $*$ LOW

This hierarchy defines Mid vowels as the most marked, and penalizes having more than one height specification within the stem. Every height specification incurs a violation. The tableaux in (9) and (10) show how these constraints

3 The analysis of VHH developed in this section will not address the front-back asymmetry illustrated in (2f) vs. (2g), as my account is not essentially different from that of Beckman (1997). Indeed, as Kaun $(1995,2004)$ shows, this asymmetry is common in [round] vowel harmony, cross-linguistically. 
account for harmony in -petela 'sift for' vs. -pindika 'be bendable' (see (2a) and (2d), above): ${ }^{4}$

(9) (Beckman 1997: fig (38), using Shimakonde stem)

\begin{tabular}{|c|c|c|c|c|}
\hline -pet-il-a/ & IDENT-S1(hi) & $*$ Mid & $*$ HIGH & IDENT(hi) \\
\hline $\begin{array}{c}\text { a.-Ce C iC - } \\
\text { I } \\
\text { Mid Hi }\end{array}$ & & $*$ & $* !$ & $*$ \\
\hline $\begin{array}{c}\text { b. CeC e C - } \\
\text { Mid }\end{array}$ & & $*$ & $*$ & $*$ \\
\hline $\begin{array}{c}\text { c Ci C i C - } \\
\text { / } \\
\text { High }\end{array}$ & $* !$ & $* * !$ & $*$ \\
\hline $\begin{array}{c}\text { d Ce C e C - } \\
\text { I } \\
\text { Mid Mid }\end{array}$ & & & $*$ \\
\hline
\end{tabular}

In tableau (9), candidate (b) is optimal, as harmonizing to the Root-initial vowel through autosegmental feature sharing minimizes the number of distinct vowel height specifications in the harmonizing domain while maintaining the input height of the Root-initial vowel.

(10) ROB tableau (Beckman 1997: fig (30), using Shimakonde stem)

\begin{tabular}{|c|c|c|c|c|}
\hline /-pind-ek-a/ & IDENT-S1(hi) & *MID & *HIGH & IDENT(hi) \\
\hline $\begin{array}{c}\text { a.- } \mathrm{C} \text { i C i C - } \\
\mathrm{Hi} \\
\mathrm{Hi}\end{array}$ & & & $* * !$ & $*$ \\
\hline $\begin{array}{c}\backslash \text { b. Ci C i C - } \\
\backslash / \\
\mathrm{Hi}\end{array}$ & & & $*$ & $*$ \\
\hline $\begin{array}{c}\text { c.C eC e C - } \\
\mid / / \\
\text { Mid }\end{array}$ & *! & $*$ & & $*$ \\
\hline $\begin{array}{c}\text { d.-Ci C e C - } \\
|+| \\
\text { Hi Mid }\end{array}$ & & $* !$ & $*$ & \\
\hline
\end{tabular}

4 In the tableaux, Mid is an abbreviation for the Aperture features [-high], [+low]. Beckman (1997) assumes standard SPE-style vowel height specifications, grouped into an Aperture node. 
The tableau in (10) illustrates that Root-initial high vowels optimally trigger the same kind of autosegmental spreading harmony, even if we assume, following Richness of the Base (ROB) that the affixal vowel is Mid in the input. Candidate (b) is again optimal, as the Root-initial vowel height feature is optimally shared by all vowels in the harmonizing domain.

To account for the inertness and opacity of [a], Beckman (1997) stipulates that the Faithfulness constraint, IDENT(low), is high ranked:

(11) $\operatorname{IdENT}($ low):

The input and output of a vowel must have the same [low] specification.

This constraint must be considered a stipulation, as otherwise [high] is the active feature in VHH. As shown in (12) and (13), ranking this constraint above the height markedness constraints blocks [a] from being an optimal trigger or target for harmony:

(12) Beckman (1997: fig (34), with Shimakonde stem in (2e))

\begin{tabular}{|c|c:c|c|c|c|}
\hline /-pat-el-a/ & IDENT-S1(hi) & IDENT(low) & $*$ Mid & $*$ High & IDENT(hi) \\
\hline $\begin{array}{c}\text { a.-Ca C i C - } \\
\text { Lo Hi }\end{array}$ & & & & $*$ & $*$ \\
\hline $\begin{array}{c}\text { b. CaC a C } \\
\text { / } \\
\text { Lo }\end{array}$ & & $* !$ & & & $*$ \\
\hline $\begin{array}{c}\text { c.-Ca C e C - } \\
\text { । } \\
\text { Lo Mid }\end{array}$ & & & $* !$ & & $*$ \\
\hline
\end{tabular}

Candidate (12a) is optimal, as it does not violate any of the highest ranked constraints. The role of IDENT(low) in optimizing the inertness of [a] is highlighted by candidate (b), which shows that harmonizing to agree with a low Root-initial vowel violates this constraint. Candidate (c) is non optimal as the vowels in the harmonizing domain are not identical in height.

Similarly, in tableau (13), IDENT(low) optimizes candidate (a), in which [a] does not undergo harmony to the Root-initial vowel and also blocks harmony to subsequent vowels in the harmonizing domain. 
(13) Beckman (1997: fig (35), with Shimakonde stem)

\begin{tabular}{|c|c|c|c|c|c|}
\hline /-lekan-il-a/ & $\begin{array}{c}\text { IDENT- } \\
\text { S1(hi) }\end{array}$ & $\begin{array}{c}\text { IDENT } \\
\text { (low) }\end{array}$ & $*$ Mid & $*$ HIGH & IDENT(hi) \\
\hline $\begin{array}{c}\text { a..-Ce C a C i C - } \\
\text { Mid Lo Hi }\end{array}$ & & & $*$ & $*$ & \\
\hline $\begin{array}{c}\text { b. Ce Ce C e C- } \\
\text { । / } \\
\text { Mid }\end{array}$ & & $* !$ & $*$ & & $*$ \\
\hline $\begin{array}{c}\text { c.-C e C a C e C - } \\
\text { । । } \\
\text { Mid Lo Mid }\end{array}$ & & & $* * !$ & & $*$ \\
\hline
\end{tabular}

As we can see from these tableaux, if we took IDENT(low) out of the ranking, total assimilation of the suffix vowel(s) would be optimal, as in (12b), (13b).

To sum up Beckman's (1997) analysis, a high-ranked Positional Faithfulness constraint (IDENTS1) accounts for the Root-controlled property of VHH. The motivation for harmony is to minimize the number of different vowel height specifications in the Stem (this minimizes violations of the HEIGHT MARKEDNESS : DOMINANCE HIERARCHY (8c)). Only Mid vowels are involved in VHH because these vowels are most marked. Low vowels are inert and opaque due to a special high-ranked Faithfulness constraint, IDENT(low).

While the analysis works very well for these basic patterns, there are conceptual reasons to be dissatisfied with it. First, it provides no explanation for why Mid vowels are marked: this is just a stipulation of the HEIGHT MARKEDNESS : DOMINANCE HIERARCHY (8c). Neither the inertness nor the opacity of [a] receive an explanation. This is just stipulated by the ranking of IDENT(low). ${ }^{5}$ Crosswhite (2003) shows that, even though Shimakonde has the same basic VHH pattern as Shona, Beckman's (1997) analysis cannot be extended to account for the way that vowel reduction interacts with VHH in Shimakonde. Notice in (5) that the vowel reduction data obviously contradict Beckman's proposal that Root-driven harmony is motivated by Positional Faithfulness. The Root-initial syllable undergoes neutralization - in violation of IDENTS1, yet the penult suffixal vowel retains the Root-controlled harmonic quality. Further, no factorial typology based on Beckman's analysis of the unreduced VHH pattern can account for the choice of reduced vowel. For [a] to be the optimal reduced vowel, some constraint defining [a] as unmarked must

5 These problems for Beckman's (1997) analysis are partly inherent to the SPE features that she adopts. See Goldsmith 1985, Harris 1994, 1997, Harris \& Lindsey 1995, 2000, Hyman 1999 and Steriade 1995 for detailed discussion. 
outrank IDENT(low) to account for why non-alternating Root [a] remains inert and opaque. As Crosswhite (2003) points out, simply adding the high-ranked licensing constraint in (14) to the analysis does not automatically optimize [a] as the reduced vowel because [a] is not the unmarked vowel in Beckman's analysis; [+high] vowels are.

(14) LiC/STRESS: A mid vowel is licensed if it is associated with a stressed syllable.

Other rankings cannot be changed. Recall that the relative ranking of *MID $>>$ *HIGH is fixed. The ranking of IDENT(low) is also fixed, in order to account for the consistent inertness and opacity of [a]. This inflexibility of most of the constraint rankings is what makes it impossible to devise a factorial typology based on Beckman's analysis that can account for the reduced vowel harmony pattern. These points are made explicit in the tableau in (15), where the bomb indicates the candidate which is incorrectly chosen as optimal in the analysis:

\begin{tabular}{|c|c|c|c|c|c|c|}
\hline /-pet-il-a/ & $\begin{array}{c}\text { LIC/ } \\
\text { STRESS }\end{array}$ & $\begin{array}{l}\text { IDENT- } \\
\text { S1(hi) }\end{array}$ & $\begin{array}{l}\text { IDENT } \\
\text { (LOW) }\end{array}$ & $* \mathrm{MID}$ & $* \mathrm{HIGH}$ & IDENT(hi) \\
\hline $\begin{array}{c}\text { a.-Ce } \mathrm{C} \text { iC - } \\
\text { Mid Hi }\end{array}$ & $* !$ & & & * & $*$ & \\
\hline $\begin{array}{l}\text { b. } \\
\text { CeC e C - } \\
\backslash / \\
\text { Mid }\end{array}$ & $* !$ & & & * & & $*$ \\
\hline $\begin{array}{l}\text { o*c } \\
\text { Ci C i C - } \\
\mid / / \\
\text { High }\end{array}$ & & $*$ & & & $*$ & $*$ \\
\hline $\begin{array}{c}\mathrm{d} \text { Ci C e C - } \\
\mid \\
\text { High Mid }\end{array}$ & & * & & $* !$ & & $*$ \\
\hline $\begin{array}{l}\text { CaC e C - } \\
|| \mid \\
\text { Low Mid }\end{array}$ & & * & *! & $*$ & & $* *$ \\
\hline
\end{tabular}


As we can see, simply adding high-ranked LiC/STRESS (14) to the analysis wrongly predicts reduction in both the Root-initial vowel and suffix vowel. Further, the optimal reduction target is a [+high] vowel due to the fixed ranking of the HEIGHT MARKEDNESS : DOMINANCE HIERARCHY (8c).

Crosswhite's $(2001,2003,2004)$ theory of vowel reduction typologies also cannot explain why reduction results in [a] and not some other vowel. In Crosswhite's typology, there are two types of vowel reduction. In prominence reducing languages, reduction results in either [+high] vowels or schwa, the shortest vowels. This type of reduction is typically found in languages where unstressed vowels are 'extremely short.' In contrast-enhancing languages, reduction results in the peripheral vowels $-[i, \mathrm{u}, \mathrm{a}]$. Shimakonde reduction fits the contrast-enhancing pattern. The problem is that since all peripheral vowels are potential targets, there is no explanation for why [a] - the longest and most sonorous peripheral vowel - is the optimal target for reduction. As we shall see, one of the advantages of the analysis developed in the next sections is that it provides a ready explanation for why only [a] is the target for reduction in Shimakonde. Another is that it defines a ranking typology that accounts for the interaction of vowel reduction with $\mathrm{VHH}$.

\subsection{Element theory and positional licensing of markedness drive VHH}

Both the reduced and unreduced Shimakonde vowel harmony patterns can be straightforwardly related in a non-derivational OT analysis, if we follow a different way of thinking about Bantu VHH argued for in work like: Goldsmith (1985), Harris (1987, 1994, 1997, 2005), Harris and Lindsey (1995), Hyman (1998, 1999), and Steriade (1995). What these researchers observe is that Rootinitial syllables contain the full set of vowel contrasts. Harmony represents a neutralization of contrasts, as it makes the quality of suffix vowels predictable from the Root. Further, non-peripheral vowels occur in suffixes only if a nonperipheral vowel also occurs in Root-initial position.

The element theory of vowel representation (see, e.g., Anderson \& Ewen 1987; Goldsmith 1985; Harris 1990, 1994, 1996, 1997; Harris \& Lindsey 1995, 2000; van de Weijer 1994) and theories of complexity licensing which they implement (see, too, van der Hulst \& Ritter 1999a, b) makes the markedness asymmetry between peripheral and non-peripheral vowels which drives Bantu vowel harmony explicit. The essential proposals of these works which are crucial to this analysis are summarized in (16): 
(16) Element theory and licensing

\section{Elements}

(a) Peripheral vowels are simplex elements: A, I, U

(b) Mid vowels are complex, consisting of a head (underlined) and a dependent:

$\mathrm{e}=[\mathrm{A}, \underline{\mathrm{I}}]$

$\mathrm{o}=[\mathrm{A}, \underline{\mathrm{U}}]$

\section{Licensing}

(c) Simplex segments with elements on only one tier, Head or Dependent, have no special constraints on their distribution, but complex segments, with elements on both the Head and the Dependent tier, often require special licensing:

(ci) Either they are directly licensed, by occurring in a strong position, like Root-initial position or a stressed syllable;

(cii) Or they are indirectly licensed, for example, by being linked to a complex vowel in a strong position.

That is, in this theory, peripheral vowels are less marked because they are simplex, while the Mid vowels are complex. Mid vowels are the only ones involved in harmony, because the dependent element of complex vowels requires licensing, and can be licensed by spread. [A] is inert for the same reason that $[\mathrm{I}, \mathrm{U}]$ are inert: it is simplex and only complex vowels need to be licensed. [A] is opaque because it is simplex: it cannot license adjacent complex vowels.

These generalizations about VHH are formalized by the constraints below:

\section{Faithfulness Constraint:}

(17) FAITH S1-[A] (adapted, Beckman 1997): Dependent input and output vocalic elements of the Root-initial syllable must be identical.

\section{Licensing Constraint motivating $\mathrm{VHH}^{6}$}

(18) LIC/SPREAD (Harris 1994, 1997; Walker 2005): A dependent vocalic element is licensed if it is associated (by multiple-linking) to every vowel in the relevant prosodic domain (e.g., harmonizing domain).

6 Precedents for this constraint include Hyman's (1998) PlATEAU constraint and Goldsmith's (1985) suggestion that complex vowels are unstable, and can be "propped up" by being linked to other complex vowels. And work like Steriade (1994, 1995), Kaun $(1995,2004)$ and Walker (2005) argues there is a perceptual reason why marked vowels are optimally linked together: marked vowels are harder to perceive and having a longer duration - by occurring in a sequence of equally marked vowels - enhances their perceptibility. 
The tableau in (19) exemplifies the analysis with a stem with a Root-initial Mid vowel; cf. (9), above:

\begin{tabular}{|c|c|c|}
\hline /-pet-il-a/ & FAITH S1-[A] & LIC/SPREAD \\
\hline 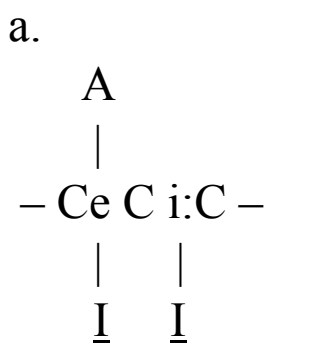 & & $* !$ \\
\hline 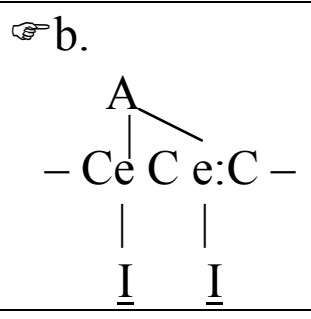 & & \\
\hline $\begin{array}{l}\text { c. } \\
-\mathrm{C} \text { i C i: } \mathrm{C}- \\
\qquad / / \\
\underline{I}\end{array}$ & $* !$ & \\
\hline
\end{tabular}

Candidate (b) is optimal, as it satisfies FAITHS1 and LIC/SPREAD, which require the dependent element of the Root-initial Mid vowel to be multiply linked. Candidate (a) is not optimal, as the dependent element is not licensed by multiple linking, while candidate (c) is not optimal, as the Root-initial vowel has not retained its input elements.

Tableau (20) illustrates that the analysis also correctly accounts for the lack of harmonic spreading found with [high] vowels: 
(20) ROB tableau

\begin{tabular}{|c|c|c|}
\hline /-pind-ek-a/ & FAITH S1-[A] & LIC/SPREAD \\
\hline 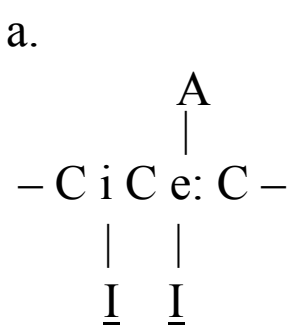 & & $* !$ \\
\hline $\begin{array}{rr}-\mathrm{Ci} & \mathrm{C} \text { i:C }- \\
\mid & \mid \\
\underline{I} & \underline{I}\end{array}$ & & \\
\hline $\begin{array}{l}\text { c. } \\
\left.{ }_{\mathrm{I}}\right|_{\mathrm{I}} ^{\mathrm{A}} \\
\mathrm{I}: \mathrm{C}-\end{array}$ & $* !$ & \\
\hline
\end{tabular}

Candidate (b) is optimal, as simplex vowels do not need to be licensed. Candidates (a) and (c) each violate one of the two highest ranked constraints.

The analysis of the inertness and opacity of [a] requires two new constraints:

(21) OCP: * $\left[\underline{X}_{i}, X_{i}\right]$ : Complex vowels with identical Head and Dependent element are marked. (adapted, Harris 1994, 1997)

(22) FAITH-HEAD: A vowel must be associated with the same Head element(s) in the input and output. 
(23) Inertness of [a]

\begin{tabular}{|c|c|c|c|}
\hline /-pat-il-a/ & FAITH S1-[A] & LIC/SPREAD & FAITH-HEAD \\
\hline $\begin{array}{rrr}-\mathrm{C} \text { a } & \mathrm{C} \text { i:C }- \\
\mid & \mid \\
\underline{A} & \text { I }\end{array}$ & & & \\
\hline - $\underset{1}{\mathrm{C}} \underset{\mathrm{A}}{\mathrm{A}} \mathrm{a}: \mathrm{C}-$ & & & $* ! *$ \\
\hline$-\mathrm{C} \mathrm{a} \mathrm{C} \mathrm{e:} \mathrm{C}-$ & & & *! \\
\hline
\end{tabular}

Candidate (a), with no harmony or assimilation, is optimal, as it does not violate any constraints. Candidates (b) and (c), which both illustrate vowel harmony, are non-optimal as they violate FAITH-HEAD.

The next tableau shows how the analysis also accounts for the blocking effect of $[\mathrm{a}]$ :

(24) Blocking by [a]

\begin{tabular}{|c|c|c|c|c|}
\hline /-lekan-il-a/ & $\begin{array}{c}\text { FAITH S1- } \\
{[\mathrm{A}]}\end{array}$ & $\mathrm{OCP}$ & LIC / SPREAD & FAITH-HEAD \\
\hline 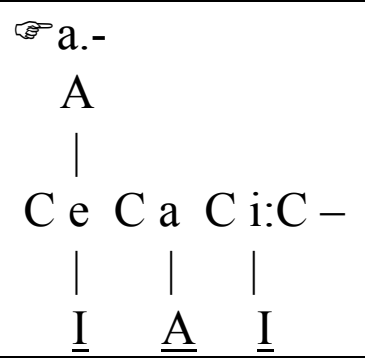 & & & $* *$ & \\
\hline 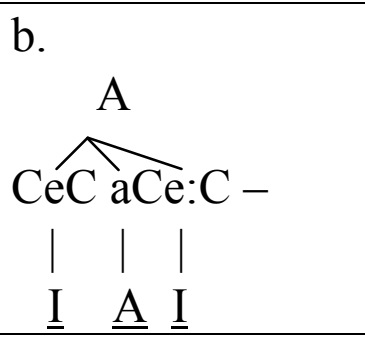 & & *! & & \\
\hline 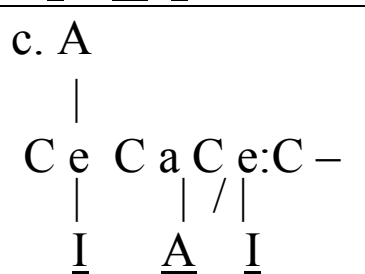 & & & $* *$ & $* !$ \\
\hline
\end{tabular}


Candidate (a) with no harmony is optimal, as the only complex vowel in this output is licensed by association to Root-initial position. Candidate (b) crucially shows the role of the OCP constraint (21) in optimizing opaque [a] in VHH, while candidate (c) fatally violates FAITH-HEAD.

To sum up this section, we have seen that both Beckman's (1997) analysis and the element analysis of Bantu VHH developed here are equally successful in accounting for the basic harmony patterns. In the next section, I show that the element analysis can easily be extended to account for the interaction of vowel reduction and coalescence with VHH. Recall that Crosswhite (2003) shows this is impossible in Beckman's (1997) approach. As we will see, the interactions of both vowel reduction and vowel coalescence with VHH are not opaque in this analysis, a further advantage of the licensed elements approach.

\section{Extending the analysis to clarify reduction, coalescence, and their interaction with $\mathrm{VHH}$}

\subsection{Reduction}

As shown in (25), in the Element theory of vowel representation, what unifies the unreduced and reduced harmony patterns in Shimakonde is that a dependent [A] must be associated with every vowel in the harmonic domain (in square brackets) in both patterns. Only Mid vowels are involved in both harmony and reduction, as they have a dependent [A] which requires licensing. What distinguishes the patterns is that the stressed syllable - the lengthened penult - is the primary licensor of complex vowels in the reduced pattern, not the Rootinitial syllable: ${ }^{7}$
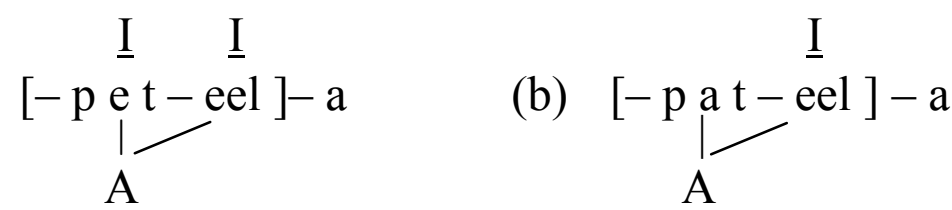

In (25) we see reduction in a disyllabic stem, where unreduced (25a) and reduced (25b) are the only two variants. However, as Liphola (2001: 170) shows, more variation is possible in longer stems:

7 As an aside, we might speculate that the reduction pattern developed when speakers at some point decided that the stressed penult was not just an 'accidental' end point for the domain of $\mathrm{VHH}$, morphologically-defined, but the licensor of a harmonizing quality that is contributed, in the input, by a vowel at the opposite edge of the domain. 
(26)

(a)

kú-pélévélélééla 'to not reach a full size for'

kú-pálévélélééla

kú-pálávélélééla

kú-páláválélééla

kú-páláválálééla

*kú-pélévélálééla (etc.).

(b)
kú-tót-édy-aana
'to cause each other to sew'
$\sim$ kú-tátédyaana
$\sim$ kú-tátádyaana
* kú-tótádyaana

Liphola (2001) observes that the generalization describing possible reduction patterns is that reduction applies contiguously from the Root-initial vowel towards the stressed vowel. In the analysis developed here, one can recast this generalization in terms of licensing of complex vowels. The element representations of the unreduced forms in (26), is given below:

(27) (a)

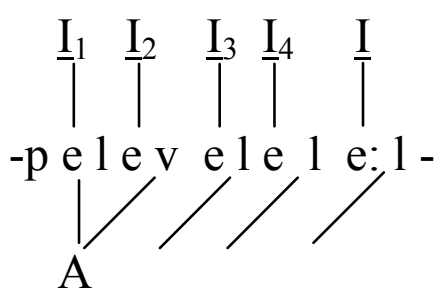

(b)

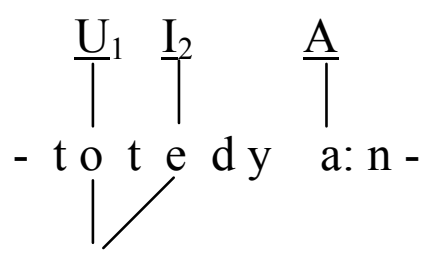

A

Comparing these structures with the reduced variants, one observes a progressive strengthening of the capacity to license Heads and complex vowels as one moves towards the stressed vowel from the Root-initial vowel.

Similar patterns of stressed vowels attracting or licensing a harmonizing feature have been described for Spanish and Italian metaphony dialects (Hualde 1989; Walker 2005; Zubizaretta 1979). I adopt here the left-branching binary metrical representation of stress licensing motivated in Zubizaretta's (1979) analysis of Andalusian Spanish vowel harmony. As we can see in (28), below, this theory of metrical representations allows the metrical motivation for contiguity of reduction to be very clearly formalized. The Root-initial syllable is metrically weakest, and metrical strength increases contiguously from the Rootinitial through the stressed vowel. The progressive increase in metrical strength mirrors the contiguous potential realization of reduced vowels: 
(28)

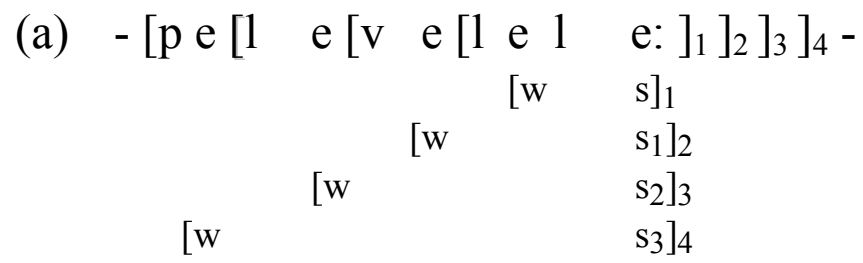

(b) $-\left[\mathrm{t} \text { o }[\mathrm{te} \text { d y } \mathrm{a:}]_{1}\right]_{2}-$

$\left[\begin{array}{ll}\mathrm{w} & \mathrm{w} \\ & \left.\mathrm{s}_{1}\right]_{2}\end{array}\right.$

The constraints in (29) formalize the proposal that the relative ability of a position to licence a complex (Mid) vowel or Head element depends on its relative metrical strength (as represented in (28)). STRESS/LICENSING A (29a) optimizes reduction by penalizing an output in which the stressed vowel is not at least as complex as the unstressed vowels in the domain. One could reduce a complex vowel to a simplex vowel by deleting either the Head element or the Dependent element. As we see in (25), above, vowel reduction in Shimakonde involves deleting a Head element, maintaining the multiply-linked Dependent element of complex Mid vowels. Stress/Licensing B (29b) accounts for the contiguity of reduction: it is violated if a vowel with a Head element is followed by a (metrically stronger) vowel lacking a Head element:

\section{(29) Licensing Constraints motivating reduction}

(a) STRESS/LiCENSING A (adapted, Harris 1990, 1996, 1997, 2005):

Within the licensing domain, a vowel in the metrically strongest position must not be elementally less complex than vowels in metrically weaker positions.

(b) STRESS/LICENSING B:

Within the licensing domain, a Head element for a vowel in a metrically weak position is licensed by a Head element in the adjacent metrically stronger position.

To complete the analysis, we must account for the variability we find in reduction: any contiguous string of vowels from the Root to the stressed vowel can be reduced. The constraint conjunction in (30) optimizes this variation. ${ }^{8}$

8 See work like Downing (1998, 2000), Itô \& Mester (2003b), Odden (2006), along with references cited in these works, for detailed motivation and exemplification of constraint conjunction in OT. 
(30) FaithHead (22) $\cup$ StRess/Licensing A

This constraint conjunction is satisfied if FAITHHEAD is satisfied (and then violations of STRESS/LICENSING A do not count) OR if STRESS/LICENSING A (and then violations of FAITHHEAD do not count). The conjunction is violated if the constraint in each half incurs violations.

FAITHHEAD (22) is involved in the conjunction, because reduction necessarily violates this constraint. The conjunction in (30) must be ranked below LIC/SPREAD (18), as this constraint is the one which optimizes retaining the dependent vowel element under reduction. (The dependent element is the one licensed by multiple linking.) The conjunction makes it optimal for variants to violate FAITHHEAD, if that leads to more optimal satisfaction of STRESS/LiCENSING A. That is, reduction is optimal if the output contains less complex vowels in the metrically weak positions compared to the strongest position. Impossible variants are 'the worst of the worst': candidates which are non-optimal both for FAITHHEAD AND STRESS/LiCENSING A. These would be candidate outputs where metrically strong positions have undergone reduction while metrically weak positions have not. STRESS/LICENSING B is ranked above the conjunction, as it is not violated in optimal candidates. That is, acceptable reduction variants must satisfy STRESS/LICENSING B by having Head elements contiguously cluster at the stressed right edges of the harmonic domain. (And, of course, they must also optimally satisfy higher ranked constraints.) These constraint rankings are summarized below:

(31) Constraint ranking accounting for vowel reduction

FAith S1-[A], LiC/SPREAD $>$ STRESS/LICENSING B $>$ FAITHHEAD $\cup$ STRESS/LICENSING A

The tableau in (32) exemplifies the analysis. Candidates (b) - (d) are optimal variants because they satisfy STRESS/LiCENSING B as well as the more highly ranked constraints. Candidate (b) satisfies FAITHHEAD, as no reduction occurs in it. Candidates (c) and (d) show reduction, so necessarily violate FAITHHEAD. However, these reduction patterns - with the reduced vowels contiguously clustered at the opposite edge of the domain from the stressed vowels optimally satisfy STRESS/LiCENSING A, B. Candidate (e), with reduction in the vowel next to the stressed vowel only, is a non-optimal variant, as it incurs violations of STRESS/LICENSING B: vowels in relatively weak positions are complex (and have Heads) while a relatively strong position has a reduced vowel. Candidates (a) and (f) are non-optimal because failing to license the dependent element through multiple linking violates the high-ranked constraints optimizing VHH. 
Opacity is a Matter of Representation: Shimakonde Vowel Harmony and Vowel Reduction

\begin{tabular}{|c|c|c|c|c|c|c|}
\hline /-pelIvIl-Il-a/ & $\begin{array}{l}\text { FAITH } \\
\text { S1-[A] } \\
\end{array}$ & $\begin{array}{c}\text { LIC/ } \\
\text { SPREAD } \\
\end{array}$ & $\begin{array}{c}\text { STRESS/ } \\
\text { LIC B } \\
\end{array}$ & $\begin{array}{l}\text { FAITH } \\
\text {-HEAD } \\
\end{array}$ & $\cup$ & $\begin{array}{c}\text { STRESS/ } \\
\text { LIC A } \\
\end{array}$ \\
\hline $\begin{array}{l}\text { a. } \\
\begin{array}{llll}\mathrm{A} & & & \\
\mid & & & \\
-\mathrm{C} & \text { e C i C i C i: C- } \\
\mid & \mid & \mid & \mid \\
\underline{I} & \underline{I} & \underline{I} & \underline{I} \\
\end{array}\end{array}$ & & 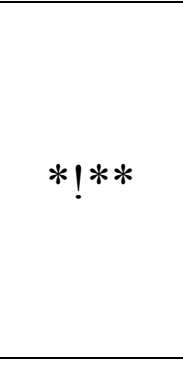 & & & & $*$ \\
\hline 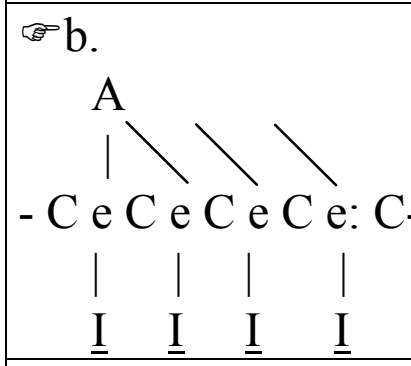 & & & & & & \\
\hline 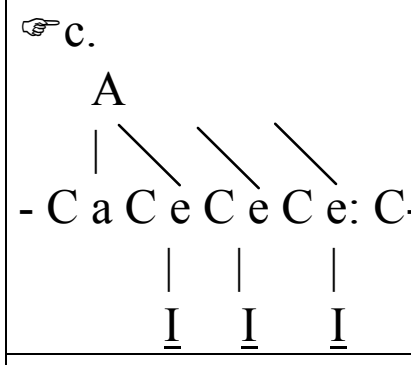 & & & & $*$ & & \\
\hline 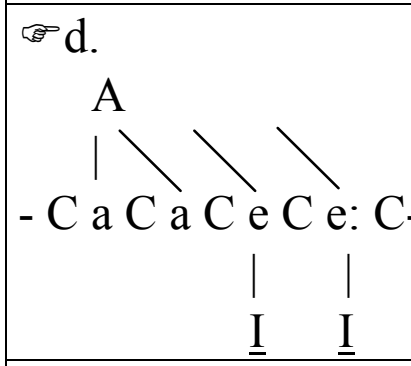 & & & & $* *$ & & \\
\hline 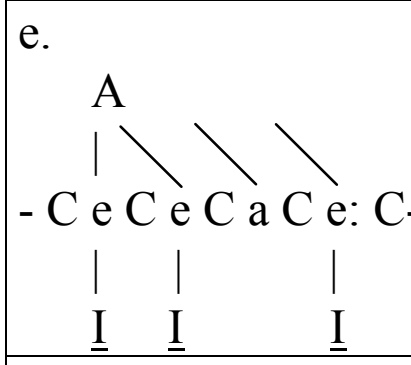 & & & $* !$ & $*$ & & \\
\hline $\begin{array}{l}\text { f. } \\
\text { - C i C i C i C i: C- } \\
\begin{array}{rllll}\mid & \mid & \mid & \mid \\
\text { I } & \underline{I} & \underline{I} & \text { I } \\
\end{array}\end{array}$ & $* !$ & & & & & \\
\hline
\end{tabular}


In sum, tableau (32) shows that the interaction of reduction with VHH need not be opaque. The analysis correctly chooses [a] as the optimal target for reduction and accounts for the attested range of variability in reduction in a nonderivational way. Recall that all of these were problems for previous analyses.

The tableau in (33) shows that the same analysis straightforwardly extends to account for the reduction pattern in (26b), data that Liphola (2001) and Ettlinger (2008) argue are problematic for an OT analysis. (Highest ranked FAITHS1-[A] is omitted from this tableau to improve readability, as it is never violated by the optimal output variants.) Candidates (b) - (d) are optimal variants because they satisfy STRESS/LICENSING B and also best satisfy the higher ranked constraints. Candidate (b) satisfies FAITHHEAD, as no reduction occurs in it. Candidates (c) and (d) show reduction, so necessarily violate FAITHHEAD. However, these reduction patterns - with Head elements contiguously clustered at the same edge of the domain as the stressed vowel - optimally satisfy StRESS/Licensing B. Candidate (e), with reduction in the vowel next to the stressed vowel only, is a non-optimal variant, as it violates STRESS/LICENSING B: the metrically weak Root-initial position has a complex vowel, while the relatively stronger position of the following vowel has undergone reduction. Candidate (a) is non-optimal, as failing to license the dependent element through multiple linking violates the high-ranked constraints optimizing VHH. (Recall that the OCP constraint accounts for the blocking effect of [a], optimizing failure to spread Dependent [A] to the final syllable in the harmony domain. $)^{9}$

9 As Liphola (p.c.) points out, this analysis does not capture that VHH is obligatory while the reduced variants are optional. How best to formalize this kind of asymmetry between variants is a topic for future research. 
(33) Opaque 'a' in harmony, reduction

\begin{tabular}{|c|c|c|c|c|c|c|}
\hline /-totIdy-an-a/ & $\mathrm{OCP}$ & $\begin{array}{c}\text { LIC/ } \\
\text { SPREAD }\end{array}$ & $\begin{array}{c}\text { STRESS/ } \\
\text { LIC B }\end{array}$ & $\begin{array}{l}\text { FAITH } \\
\text {-HEAD }\end{array}$ & $\cup$ & $\begin{array}{c}\text { STRESS/ } \\
\text { LIC A }\end{array}$ \\
\hline 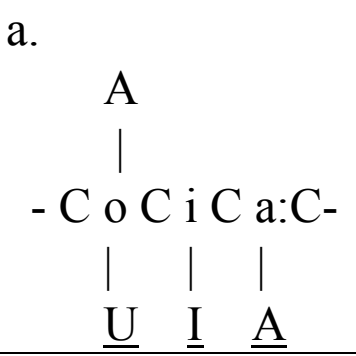 & & $* * !$ & & & & * \\
\hline 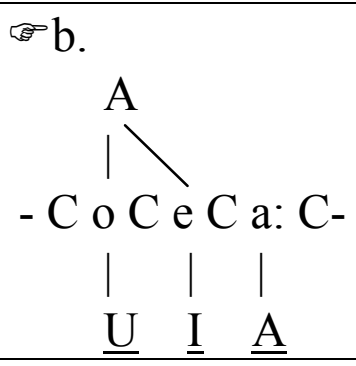 & & $*$ & & & & $*$ \\
\hline $\begin{array}{c}\mathrm{A} \\
\mid \backslash \mathrm{C} \text { a C a C a:C - } \\
\\
\underline{\mathrm{A}}\end{array}$ & & $*$ & & $*$ & & \\
\hline 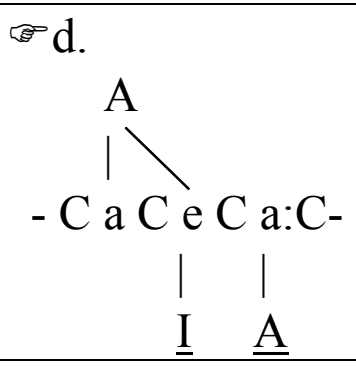 & & $*$ & & $*$ & $*$ & $*$ \\
\hline 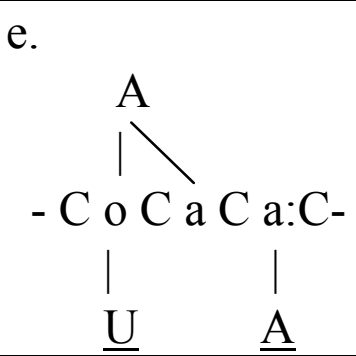 & & $*$ & $* !$ & $*$ & $*$ & $*$ \\
\hline
\end{tabular}

\subsection{Coalescence and its interaction with VHH and reduction}

As shown in section 2, the interaction between vowel reduction and VHH is not the only apparent source of derivational opacity in Shimakonde. Coalescence and its interaction with VHH and reduction, illustrated in figures (3), (4), and (7), above, also illustrate derivational opacity. Coalesced outputs contain opaque 
long vowels, and some also contain Mid vowels which do not participate in VHH or vowel reduction. In this section I show that both sources of opacity vanish, given an alternative set of representational assumptions.

\subsubsection{Clarifying coalesced vowel length}

Goldrick's (2000) claim that the lengthening which accompanies vowel coalescence is opaque crucially rests on the assumption - borrowed from McCarthy \& Prince (1986) via Rosenthall (1994: 26) - that moras are redundantly underspecified for short vowels in the input. All short vowels are optimally associated with a single mora in the output to satisfy PROJECT- $\mu$ (or VOWEL- $\mu$ ):

(34) VOWEL- $\mu$ (Rosenthall 1994: 26)

For every vocalic root node $\mathrm{rt}_{\mathrm{i}}$, there is a mora $\mu_{\mathrm{i}}$.

This analysis was illustrated in (4), above, repeated below for convenience:

(35) Opaque compensatory lengthening analysis (Goldrick 2000, fig. (2))

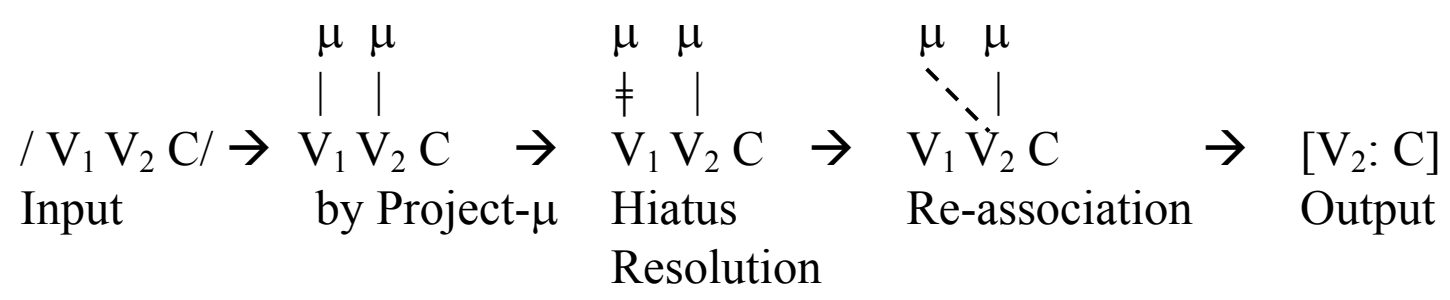

As Goldrick (2000) notes, however, Richness of the Base (Prince \& Smolensky 2004) requires us to consider two possible inputs for non-contrastive output properties like short vowel-mora association: not only the representation in (35), repeated below for ease of comparison, but also the representation in (36), with short vowels fully specified for moras (assumed by, e.g., Broselow et al. 1997):

(36) Transparent compensatory lengthening analysis

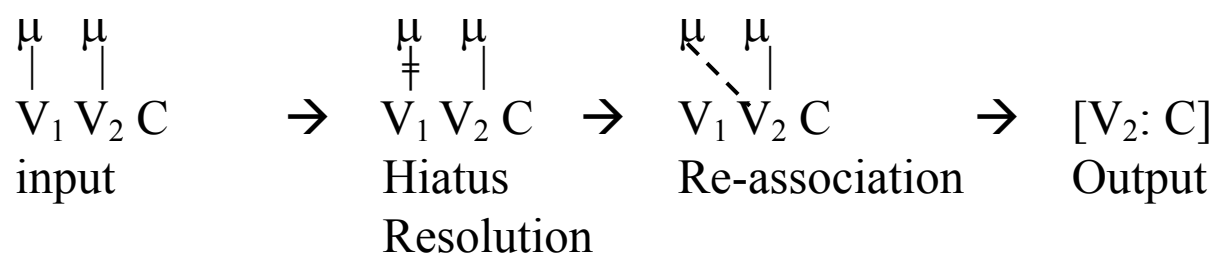

As we can see in (36), fully specifying moras in the input makes lengthening transparent in an OT account, just as it is in earlier accounts, like Clements 
(1986). Input 'timing' (CV slots or moras) of the $\mathrm{V}_{1} \mathrm{~V}_{2}$ sequence is preserved in the output (bimoraic) long $\mathrm{V}$, even though the input quality of both output vowels is not preserved. The fully-specified input in (36) not only renders lengthening transparent, it also better satisfies the principle of Lexicon Optimization (Prince \& Smolensky 2004, Kager 1999: 33) which proposes that inputs should always match outputs, barring evidence to the contrary. This principle defines redundant underspecification of inputs as generally nonoptimal, since inserting the underspecified features in the output necessarily leads to FAITHFULNESS violations which are not incurred if the input and output are identical.

To sum up this section, lengthening under coalescence is fully transparent if the optimal, fully specified input representation of vowel-mora association is adopted. Opacity is a characteristic of the underspecification analysis, not inherent to the process of compensatory lengthening.

\subsubsection{Coalescence and the representations of Mid vowels}

The data in (3) and (6), above, illustrate that coalescence can make both VHH and vowel reduction derivationally opaque. The output of coalescence is a Mid vowel, yet some coalesced Mid vowels do not participate in VHH and reduction while others do. I propose that this difference falls out in the approach adopted here, as Mid vowels which have coalescence of $[a+i / u]$ as their source have a different representation from other Mid vowels.

In Element theory, coalescence can be analyzed as the fusion of two heads (see, e.g., Anderson \& Ewen 1987), to satisfy the high-ranked constraint in (37):

COALESCE: *Onsetless syllables and *Diphthongs.

The output of coalescence maintains the input headedness of the vowels, as shown in (38):

(38) Representation of coalesced mid vowels (compare with (16b))

$$
\begin{aligned}
& \mathrm{e}=[\underline{\mathrm{A}}, \underline{\mathrm{I}}] \\
& \mathrm{o}=[\underline{\mathrm{A}}, \underline{\mathrm{U}}]
\end{aligned}
$$

This output violates the markedness principle in (39a) on element combinations, requiring them to have one and only one head. To make coalescence, rather than, say, vowel deletion the optimal repair for violations of the constraints abbreviated in (37), the FAITH constraint in (39b) must outrank HEAD: 
(39)

(a) HEAD: Phonological entities have one and only one head. outranked by:

(b) MAX-Voc: All input vocalic elements must have an input correspondent.

As harmony crucially involves the licensing of complex Mid vowels - ones with Head and Dependent elements - the inertness of Mid vowels resulting from the coalescence of $[\mathrm{a}+\mathrm{i}]$ or $[\mathrm{a}+\mathrm{u}]$ falls out transparently from the representations in (38). These Mid vowels have no dependents requiring licensing. Mid vowels resulting from coalescence of $[\mathrm{a}+\mathrm{e}]$ or $[\mathrm{a}+\mathrm{o}]$, however, have dependent elements - their representation is identical to $(16 \mathrm{~b})$ - so they still trigger $\mathrm{VHH}$ and undergo reduction.

The constraint rankings for coalescence are summarized in (40), and the tableaux in (41) and (42) exemplify the analysis. (HEAD (39b) is omitted from the tableaux, as it is too low-ranked to play a role in choosing optimal candidates):

(40) Coalescence, plus canonical vowel harmony:

COALESCE $>>>$ FAITH $[\mathrm{A}]-\mathrm{S} 1$, LIC/SPREAD $>$ STRESS/LICENSING B $>$ FAITHHEAD $\cup$ STRESS/LICENSING A $\gg$ MAX-VOC $>>$ HEAD

(41) $\mathrm{a}+\mathrm{i}$ coalescence

\begin{tabular}{|c|c|c|c|c|c|c|c|c|}
\hline /-va-nda-[im-il-a/ & $\begin{array}{l}\text { COA- } \\
\text { LESCE }\end{array}$ & $\begin{array}{c}\text { FAITH } \\
{[\mathrm{A}]-} \\
\text { S1 }\end{array}$ & $\begin{array}{c}\text { LIC/ } \\
\text { SPREAD }\end{array}$ & $\begin{array}{c}\text { STRESS } / \\
\text { LIC B }\end{array}$ & $\begin{array}{l}\text { FAITH } \\
\text { HEAD }\end{array}$ & $\cup$ & $\begin{array}{c}\text { STRESS/ } \\
\text { LIC A }\end{array}$ & $\begin{array}{l}\text { MAX- } \\
\text { VOC }\end{array}$ \\
\hline 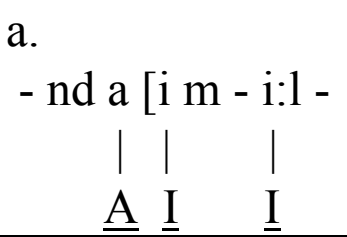 & $* !$ & & & & & & & \\
\hline 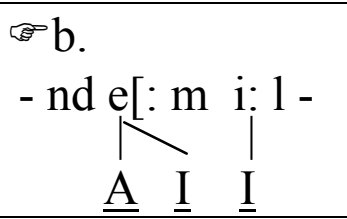 & & & & & & & & \\
\hline $\begin{array}{l}\text { c. } \\
\text { - C }[\mathrm{i}: \mathrm{m}-\mathrm{i}: 1 \text { - } \\
\mid \begin{array}{l}\mid \\
\text { I }\end{array}\end{array}$ & & & & & $*$ & & & $* !$ \\
\hline
\end{tabular}

Recall that vowels are defined as complex if they have an element on both the Head and the Dependent tier. For this reason, candidate (b) in tableau (41) is optimal. Note that it does not violate any constraints. Candidate (a), which 
matches the input, is non-optimal as it violates high-ranked COALESCE (37). Candidate (c), which resolves hiatus by deleting one of the input vowel elements, is non-optimal, as it violates MAX-Voc (39b). Note in (41) that the Mid vowel which is the output of coalescence is not associated with a Dependent vowel, so VHH is not expected.

In contrast, $\mathrm{VHH}$ is optimal if the Mid vowel which is the output of coalescence contains an input Mid vowel with a Dependent element to be licensed. This is shown in (42):

(42) $\mathrm{a}+\mathrm{e}$

\begin{tabular}{|c|c|c|c|c|c|c|c|c|}
\hline /-va-nda-[ep-il-a/ & $\begin{array}{l}\text { COA- } \\
\text { LESCE }\end{array}$ & $\begin{array}{c}\text { FAITH } \\
\text { S1- } \\
\text { [A] }\end{array}$ & $\begin{array}{c}\text { LIC/ } \\
\text { SPREAD }\end{array}$ & $\begin{array}{l}\text { STRESS/ } \\
\text { LIC B }\end{array}$ & $\begin{array}{l}\text { FAITH } \\
\text { HEAD }\end{array}$ & $\cup$ & $\begin{array}{c}\text { STRESS/ } \\
\text { LIC A }\end{array}$ & $\begin{array}{l}\text { MAX- } \\
\text { VOC }\end{array}$ \\
\hline 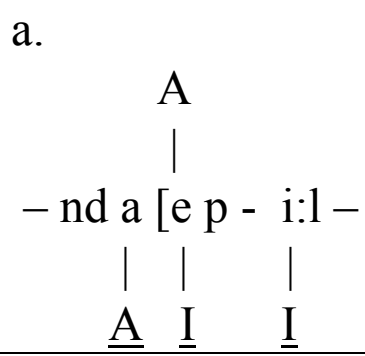 & $* !$ & & $*$ & & & & $*$ & \\
\hline 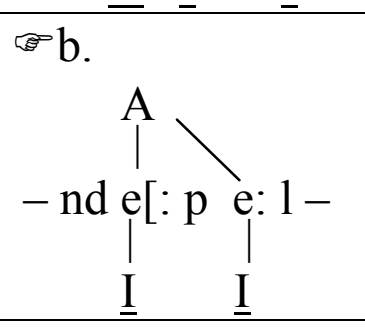 & & & & & $*$ & & & $*$ \\
\hline 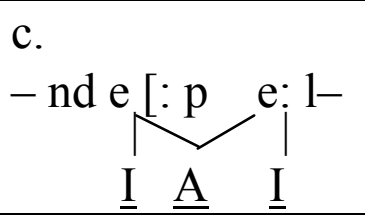 & & $* !$ & & & $*$ & & & * \\
\hline
\end{tabular}

Candidate (b) is optimal, as it violates none of the high-ranked constraints. Note that $\mathrm{VHH}$ is optimal in this candidate, as the coalesced Mid vowel has a dependent element which requires licensing. Candidate (a), which is identical to the input, is not optimal because it violates high-ranked COALESCE. Candidate (c), where the dependent element of the Root-initial syllable has been deleted, is not optimal because it violates FAITHS1-[A] (17).

The tableau in (43) shows that the analysis also transparently accounts for the interaction of $[\mathrm{a}+\mathrm{i}]$ coalescence with reduction harmony: 
(43) $a+i$ plus reduction

\begin{tabular}{|c|c|c|c|c|c|c|c|c|}
\hline $\begin{array}{l}\text { /-va-nda- } \\
\text { [im-il-a/ }\end{array}$ & $\begin{array}{l}\text { COA- } \\
\text { LESCE }\end{array}$ & $\begin{array}{c}\text { FAITH } \\
\text { S1- } \\
\text { [A] }\end{array}$ & $\begin{array}{c}\text { LIC/ } \\
\text { SPREAD }\end{array}$ & $\begin{array}{c}\text { STRESS/ } \\
\text { LIC B }\end{array}$ & $\begin{array}{l}\text { FAITH } \\
\text { HEAD }\end{array}$ & $\cup$ & $\begin{array}{c}\text { STRESS/ } \\
\text { LIC A }\end{array}$ & $\begin{array}{l}\text { MAX- } \\
\text { VOC }\end{array}$ \\
\hline $\begin{array}{l}\text { a. } \\
\text { - nd a [i m - i:1 - } \\
\qquad \begin{array}{rrr}\mid & \mid \\
\underline{\mathrm{A}} & \underline{\mathrm{I}} & \underline{\mathrm{I}}\end{array}\end{array}$ & $* !$ & & & & & & & \\
\hline 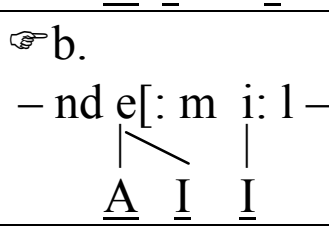 & & & & & $*$ & & & \\
\hline $\begin{array}{l}\text { c. } \\
\text { - nd a: }[\mathrm{m}-\mathrm{i}: 1 \text { - } \\
\underline{\mathrm{A}}\end{array}$ & & & & & $*$ & & & $* !$ \\
\hline
\end{tabular}

Candidate (b) is optimal, as it violates none of the constraints. Candidate (a), which is identical to the input, is not optimal because it violates high-ranked COALESCE. Candidate (c), with reduction to [a], is non-optimal because this violates MAX-VOC (39b).

To sum up, we have seen that adopting the element theory of vowel representations, with its crucial distinction between Head and Dependent elements, makes the relation between reduced and unreduced vowel harmony patterns transparent. In all surface variants, a dependent [A] element is licensed by spread to all vowels in the domain (subject to the OCP). Heads must also be licensed: they must either be in the metrically strongest position or adjacent to a Head in a metrically stronger position. This explains the Contiguity of reduced vowels. Coalesced Mid vowels only participate in VHH and reduction when they have a Dependent element to be licensed by harmony. None of the processes is derivationally opaque.

\section{Conclusion}

I have shown that the choice of features and the relations among segments that define optimal combinations of features are crucial to an analysis of Shimakonde vowel harmony. Element theory explains why only non-peripheral vowels participate in harmony. It also explains why [a] is the target of reduction. And it allows non-high vowels, crucially, to have two different output representations - this is why the interactions of coalescence and reduction with VHH are not opaque. Low vowels can be represented either as Head [A] or, 
more marked, as Dependent [A] (in reduction). Mid vowels can be represented either as Head/Dependent complexes or, more marked, as the fusion of two Heads (in coalescence). Further, we have a choice of representations of unbounded stress. A binary branching model, we have seen, clearly formalizes the progressive weakening in the licensing strength of vowels which are farthest from the stressed vowel. It is this choice of metrical representation which allows us to formalize contiguity of reduction in a way that is not derivationally opaque.

In short, the analysis shows that choice of input and output representations is as important in OT as the choice of constraints evaluating the representations. Opacity can vanish with the proper choice of representations.

\section{Acknowledgements}

Earlier versions of this paper were presented at the Sound Circle, Amsterdam, the $14^{\text {th }}$ Manchester Phonology Meeting, OCP 3 in Budapest, a Potsdam Phonology Colloquium and the Workshop on the Phonological Bases of Phonological Features, Tromsø. I would like to thank the audiences at these talks - in particular, Jill Beckman, Ricardo Bermúdez-Otero, Paul Boersma, Ben Hermans, Larry Hyman, Bruce Morén, David Odden, Marc van Oostendorp, Donca Steriade, Jochen Trommer and Jeroen van de Weijer - as well as Marc Ettlinger, Marcelino Liphola, Sabine Zerbian, Eva Zimmermann and the editors of this volume - for helpful comments and questions. Any errors of fact or interpretation are, of course, my responsibility.

\section{References}

Anderson, John \& Colin Ewen (1987). Principles of dependency phonology. Cambridge: Cambridge University Press.

Baković, Eric (2007a). A revised typology of opaque generalisations. Phonology 24, 217259.

Baković, Eric (2007b). Local assimilation and constraint interaction. In: Paul de Lacy (ed.), The Cambridge Handbook of Phonology. Cambridge: Cambridge University Press, 335-352.

Barnes, Jonathan (2006). Strength and Weakness at the Interface: Positional Neutralization in Phonetics and Phonology. Berlin: Mouton de Gruyter.

Beckman, Jill N. (1997). Positional faithfulness, positional neutralization and Shona vowel harmony. Phonology 14, 1-46.

Bermudez-Otero, Ricardo (In preparation). Stratal Optimality Theory. (Oxford Studies in Theoretical Linguistics). Oxford: Oxford University Press.

Broselow, Ellen, Su-I Chen \& Marie Huffman (1997). Syllable weight: convergence of phonology and phonetics. Phonology 14, 47-82. 
Casali, Roderic F. (1998). Resolving Hiatus. New York: Garland.

Clements, G.N. (1986). Compensatory lengthening and consonant gemination in LuGanda. In: Leo Wetzels \& Engin Sezer, eds. Studies in Compensatory Lengthening. Dordrecht: Foris, 37-77.

Crosswhite, Katherine (2001). Vowel reduction in Optimality Theory. London: Routledge.

Crosswhite, Katherine (2003). Vowel reduction in Shimakonde. CASTL Kick-off Conference, University of Tromsø, 2-4 October 2003.

Crosswhite, Katherine (2004). Vowel reduction. In: Bruce Hayes, Robert Kirchner \& Donca Steriade (eds.), Phonetically Based Phonology, Cambridge: Cambridge University Press, 191-231.

Downing, Laura J. (1995). The Tonal Phonology of Jita. Munich: Lincom Europa.

Downing, Laura J. (1998). On the prosodic misalignment of onsetless syllables. NLLT 16, 152.

Downing, Laura J. (1999). Prosodic Stem $\neq$ Prosodic Word in Bantu. In: T. Alan Hall \& Ursula Kleinhenz (eds.), Studies on the Phonological Word. Amsterdam: John Benjamins, 73-98.

Downing, Laura J. (2000). Morphological and prosodic constraints on Kinande verbal reduplication. Phonology 17, 1-38.

Downing, Laura J. (2005). On the ambiguous segmental status of nasals in homorganic NC sequences. In: Marc van Oostendorp \& Jeroen van de Weijer (eds.) The Internal Organization of Phonological Segments. Berlin: Mouton de Gruyter, 183-216.

Downing, Laura J. (2006). Canonical Forms in Prosodic Morphology. Oxford: Oxford University Press.

Ettlinger, Marc (2008). Input Drive Opacity. Ph.D. dissertation, University of CaliforniaBerkeley.

Goldsmith, John (1985). Vowel harmony in Khalkha Mongolian, Yaka, Finnish and Hungarian. Phonology Yearbook 2, 253-275.

Goldrick, Matthew (2000). Turbid Output Representations and the Unity of Opacity. In: Proceedings of NELS 30, 231-245.

Green, Antony D. (2007). Phonology Limited. Potsdam: Universitätsverlag Potsdam.

Hargus, Sharon \& Virginia Beavert (2006). Word-initial clusters and minimality in Yakima Sahaptin. Phonology 23, 21-58.

Harris, John (1987). Non-structure-preserving rules in Lexical Phonology: Southeastern Bantu Harmony. Lingua 73, 255-292.

Harris, John (1990). Segmental complexity and phonological government. Phonology 7, 255300.

Harris, John (1994). Monovalency and opacity: Chichewa height harmony. UCL Working Papers in Linguistics, 509-547. 
Harris, John (1996). Phonology output is redundancy-free and fully interpretable. In: Jacques Durand \& Bernard Laks (eds.), Current Trends in Phonology: Models and Methods. Salford: ESRI, 305-332.

Harris, John (1997). Licensing inheritance: an integrated theory of neutralization. Phonology $14,315-270$.

Harris, John (2005). Vowel reduction as information loss. In: Philip Carr, Jacques Durand \& Colin J. Ewen (eds.), Headhood, Elements, Specification and Contrastivity. Amsterdam: John Benjamins, 119-132.

Harris, John \& Geoff Lindsey (1995). The elements of phonological representation. In: Jacques Durand \& Francis Katamba (eds.), Frontiers of Phonology. London: Longman, 34-79.

Harris, John \& Geoff Lindsey (2000). Vowel patterns in mind and sound. In: Noel BurtonRoberts, Philip Carr \& Gerard Docherty (eds.), Phonological Knowledge: Conceptual and Empirical Issues, Oxford: Oxford University Press, 185-205.

Hualde, Jose Ignacio (1989). Autosegmental and metrical spreading in the vowel-harmony systems of northwestern Spain. Linguistics 27, 773-805.

van der Hulst, Harry \& Jeroen van de Weijer (1995). Vowel harmony. In: John A. Goldsmith (ed.), Handbook of Phonological Theory. Cambridge, Mass.: Blackwell, 495-534.

van der Hulst, Harry \& Nancy A. Ritter (1999a). Head-driven phonology. In: Harry van der Hulst \& Nancy A. Ritter (eds.), The Syllable: Views and Facts. Berlin: Mouton de Gruyter, 113-167.

van der Hulst, Harry \& Nancy A. Ritter (1999b). No sympathy for opacity. CLS 35:1, 153173.

Hyman, Larry M. (1998). Positional prominence and the 'prosodic trough' in Yaka. Phonology 15, 41-75.

Hyman, Larry M. (1999). The historical interpretation of vowel harmony in Bantu. In JeanMarie Hombert \& Larry M. Hyman (eds.), Bantu Historical Linguistics: Theoretical and Empirical Perspectives. Stanford: CSLI, 235-295.

Itô, Junko \& Armin Mester (1997). Sympathy theory and German truncations. In: Viola Miglio \& Bruce Morén (eds.), University of Maryland Working Papers in Linguistics $5,117-139$.

Itô, Junko \& Armin Mester (2003a). On the sources of opacity in OT: coda processes in German. In: Caroline Féry \& Ruben van de Vijver (eds.), The Syllable in Optimality Theory. Cambridge: Cambridge University Press, 271-303.

Itô, Junko \& Armin Mester (2003b). Japanese Morphophonemics: Markedness and Word Structure. Cambridge, Mass.: The MIT Press.

Kager, René (1999). Optimality Theory. Cambridge: Cambridge University Press.

Kaun, Abigail (1995). The Typology of Rounding Harmony: An Optimality Theoretic Approach. Ph.D. dissertation, UCLA. 
Kaun, Abigail (2004). The typology of rounding harmony. In: Bruce Hayes, Robert Kirchner \& Donca Steriade (eds.), Phonetically Based Phonology. Cambridge: Cambridge University Press, 87-116.

Kiparsky, Paul (2000). Opacity and cyclicity. The Linguistic Review 17, 351-365.

Kraal, Peter (2005). A Grammar of Makonde. Ph.D. thesis, University of Leiden.

Krämer, Martin. 2008. English schwa insertion before liquids and phonological opacity. Proceedings of CLS 41.1, 267-282.

Liphola, Marcelino (2001). Aspects of Phonology and Morphology of Shimakonde. Ph.D. dissertation, OSU.

McCarthy, John J. (1999). Sympathy and phonological opacity. Phonology 16, 331-399.

McCarthy, John J. (2002). A Thematic Guide to Optimality Theory. Cambridge: Cambridge University Press.

McCarthy, John J. (2003). Comparative markedness. Theoretical Linguistics 29, 1-51.

Mielke, Jeff, Mike Armstrong \& Elizabeth Hume (2003). Looking through opacity. Theoretical Linguistics 29, 123-139.

Morén, Bruce (2006). Consonant-vowel interactions in Serbian: Features, representations and constraint interactions. Lingua 116, 1198-1244.

Mutaka, Ngessimo (1994). The Lexical Tonology of Kinande. Munich: LINCOM EUROPA.

Nevins, Andrew (2007). Review of Barnes, Jonathan, Strength and Weakness at the Interface: Positional Neutralization in Phonetics and Phonology. Phonology 24, 461-469.

Odden, David (2006). Minimality and onsetless syllables in Zinza. Phonology 23, 431-441.

Orgun, Cemil Orhan (2001). English r-insertion in Optimality Theory. NLLT 19, 737-749.

Prince, Alan \& Paul Smolensky (2004). Optimality Theory: Constraint Interaction in Generative Grammar. Malden, MA: Blackwell.

Rose, Yvan (2000). Headedness and Prosodic Licensing in the L1 Acquisition of Phonology. $\mathrm{PhD}$ dissertation, McGill University.

Rosenthall, Sam (1994). Vowel/Glide Alternation in a Theory of Constraint Interaction. $\mathrm{PhD}$ dissertation, University of Massachusetts-Amherst.

Rubach, Jerzy (2003). Polish palatalization in Derivational Optimality Theory. Lingua 113, 197-237.

Steriade, Donca (1994). Positional neutralization and the expression of contrast. Ms. UCLA.

Steriade, Donca (1995). Underspecification and markedness. In: John A. Goldsmith (ed.), Handbook of Phonological Theory. Cambridge, Mass.: Blackwell, 114-174.

Uffmann, Christian (2005). Optimal geometries. In: Marc van Oostendorp \& Jeroen van de Weijer (eds.), The Internal Organization of Phonological Segments. Berlin: Mouton de Gruyter, 27-62.

Uffmann, Christian (2007). Restricting GEN. In: Sylvia Blaho, Patrik Bye \& Martin Krämer, (eds.), Freedom of Analysis? Berlin: Mouton de Gruyter, 281-312. 
Opacity is a Matter of Representation: Shimakonde Vowel Harmony and Vowel Reduction

Vaux, Bert \& Andrew Nevins, eds. (2008). Rules, Constraints, and Phonological Phenomena. Oxford: Oxford University Press.

Walker, Rachel (2005). Weak triggers in vowel harmony. NLLT 23, 917-989.

Van de Weijer, Jeroen (1996). Segmental Structure and Complex Segments. Ph.D. dissertation, HIL.

Zubizarreta, Maria Luisa (1979). Vowel harmony in Andalusian Spanish. MITWPL 1, 